\title{
Polymerization of Thiophene Derivatives Bearing Bulky Azobenzene Substituent with Flexible Alkyl Spacer in Liquid Crystal
}

\author{
Reina Ohta, Satoshi Ohkawa, Hiromasa Goto*
}

Graduate School of Pure and Applied Sciences, Institute of Materials Science, University of Tsukuba, Tsukuba, Ibaraki 305-8573, Japan

\author{
*Address Correspondence to: Graduate School of Pure and Applied Sciences, Institute \\ of Materials Science, University of Tsukuba, Tsukuba, Ibaraki 305-8573, Japan \\ E-mail: gotoh@ims.tsukuba.ac.jp
}

\begin{abstract}
A series of polythiophene derivatives bearing azobenzene moiety is synthesized in liquid crystal (LC) as a reaction medium. Infrared absorption, ultra violet-visible (UV-vis) absorption, fluorescence spectroscopies, and gel permeation chromatography for the polymers thus prepared are examined. LC temperature ranges of the reaction mixtures before and after polymerization are confirmed with differential scanning calorimetry (DSC) and visual inspection by using polarizing optical microscopy (POM) to achieve polymerization in the LC temperature range. The LC medium free polymers show nematic LC phase.
\end{abstract}

Keywords azobenzene, blue phase (BP), $\pi$-conjugated polymers, liquid crystal, optical absorption 
Ohta, R.; Ohkawa, S.; Goto, H.*

Polymerization of Thiophene Derivatives Bearing Bulky Azobenzene Substituent with Flexible Alkyl

Spacer in Liquid Crystal, Int. Nat. J. Polym. Mater. 61:395-409, 2012.

\section{INTRODUCTION}

Azobenzene are known as a photosensitive material. Many studies have been reported on synthesis of polymers bearing azobenzenes. Azobenzene in polymers functions as a photo-responsible part, which imbues changes throughout the optical properties of the entire polymer system [1-9].

Until now, many chiral conjugated polymers having chiral substituent from chiral monomers have been reported [10-13]. We have developed preparations of chiroptical conjugated polymers from achiral monomers by using cholesteric liquid crystal (CLC) [14-19].

In the present study, Migita-Kosuge-Stille type polycondensation reaction [20] for obtaining polythiophenes bearing azobenzene moiety as a bulky functional substituent in liquid crystal (LC) was carried out. We introduced alkyl chains as flexible spacer between the main-chain and the substituent for introduction of ample space and flexibility, although the azobenzene moiety was directly connected to the main-chain via ester in the previous study [17]. Herein, an introduction of an alkyl spacer allows photoisomerization of azobenzene moiety in the polymers.

Optical absorption and fluorescence spectroscopy measurements for the present polymer thus synthesized are performed to characterize optical properties. Electrospin resonance (ESR) measurements with in-situ vapor doping of iodine for the polymer is carried out to confirm generation of charge species along the $\pi$-conjugated main-chain. Differential scanning calorimetry (DSC) of the LC reaction mixtures confirmed achievement of polymerization under suitable temperature range of the LC phase. 
Ohta, R.; Ohkawa, S.; Goto, H.*

Polymerization of Thiophene Derivatives Bearing Bulky Azobenzene Substituent with Flexible Alkyl

Spacer in Liquid Crystal, Int. Nat. J. Polym. Mater. 61:395-409, 2012.

\section{RESULTS AND DISCUSSION}

\section{Synthesis of Reaction Medium and Monomers}

$(R)$ - and (S)-4-ethoxyphenyl 4'-(1-methyl heptyloxy)-biphenyl-4-carboxylate, abbreviated as $(R)$-CLC and $(S)$-CLC, for an LC medium were synthesized according to the method previously reported in the literature [14-17]. We prepared a bithiophene derivative (5,5'-bis(trimethylstannyl)-2,2'-bithiophene (SBT)) and two kinds of thiophene derivatives bearing azobenzene moiety ([6-(4-phenylazo-phenoxy) hexyl] 2,5-dibromo-3-thenoate (A6T) and [10-(4-phenylazo-phenoxy) decanyl] 2,5-dibromo-3-thenoate (A10T)) as monomers [19b, 21-23].

\section{Polymerization}

We carried out Migita-Kosugi-Stille type polycondensation reaction [20] between SBT and the thiophene derivatives bearing the azobenzene moiety in $\mathrm{LC}$ as a reaction medium. Two types of polymers were synthesized from A6T and SBT, and A10T and SBT, respectively, in (R)-CLC and (S)-CLC, as shown in Scheme 1.

In the polymerization, $(R)$-CLC or $(S)$-CLC was placed in a small Schlenk flask and temperature was maintained at the LC temperature range. After addition of the monomers, $\mathrm{Pd}(0)$ catalyst $\left[\mathrm{Pd}\left(\mathrm{PPh}_{3}\right)_{4}\right]$ were added to the $\mathrm{LC}$. The reaction mixture was slowly stirred at $75 \mathrm{rpm}$ to maintain the cholesteric LC phase. Cholesteric LC phase of the reaction mixture was confirmed by visible inspection through selective reflection of light.

After $24 \mathrm{~h}$, the reaction mixture was allowed to cool to room temperature and a small amount of acetone was added. The reaction solution was subsequently poured into a large amount of acetone and washed for ca. $4 \mathrm{~h}$. Then the stirring was stopped; the 
Ohta, R.; Ohkawa, S.; Goto, H.*

Polymerization of Thiophene Derivatives Bearing Bulky Azobenzene Substituent with Flexible Alkyl Spacer in Liquid Crystal, Int. Nat. J. Polym. Mater. 61:395-409, 2012.

flask was stationed and left for several days. The acetone was decanted off, and a large amount of acetone was added again. After washing for ca. 4h, the precipitant was collected by decantation. The crude product was washed in a large amount of methanol for ca. $4 \mathrm{~h}$. The precipitation was collected by decanting off. The desired polymers (powder form) were collected after drying under vacuum. The polymers thus obtained are abbreviated as $\operatorname{PA6T}[(R)-\mathrm{CLC}], \quad \operatorname{PA6T}[(S)-\mathrm{CLC}], \quad \operatorname{PA} 10 \mathrm{~T}[(R)-\mathrm{CLC}], \quad$ and $\operatorname{PA} 10 \mathrm{~T}[(S)-\mathrm{CLC}](\mathrm{P}=$ poly, $\mathrm{A}=\mathrm{Azo}, 6$ or $10=$ hexyl or decyl, $\mathrm{T}=$ thiophene, $[(R)-\mathrm{CLC}]$ and $[(R)-\mathrm{CLC}]$ are LC medium (LC solvent) employed for the polymerization). PA6T $[(R)-\mathrm{CLC}]$ and $\operatorname{PA6T}[(S)-\mathrm{CLC}]$ were prepared at $97{ }^{\circ} \mathrm{C}$, while PA10T $[(R)-\mathrm{CLC}]$ and PA10T $[(S)-\mathrm{CLC}]$ were prepared at $92^{\circ} \mathrm{C}$ in the $\mathrm{LC}$.

The polymers were obtained in $47-66 \%$ yield. The polymerization results are summarized in Table 1 . The number-average molecular weights $\left(M_{\mathrm{n}}\right)$ of the polymers are 1,500-2,200; the weight-average molecular weights $\left(M_{\mathrm{w}}\right)$ of the polymers are 2,100-3,500. Filtration of insoluble large molecular weight fragments was carried out prior to the GPC measurement because the polymers have low solubility in THF. Therefore, the GPC measurements were performed for low-molecular mass fraction polymers only.

IR measurements of the polymers were performed to assign the chemical structure. PA6T $[(R)-C L C]$ and PA10T $[(R)-C L C]$ show almost the same absorptions in the IR measurements. The absorption bands of PA6T[(R)-CLC] at $1707 \mathrm{~cm}^{-1}$ and $1249 \mathrm{~cm}^{-1}$ are due to $\mathrm{C}=\mathrm{O}$ stretching of the ester group. The band at $1139 \mathrm{~cm}^{-1}$ can be assigned to the $v_{(\mathrm{C}-\mathrm{O}-\mathrm{C},-\mathrm{C}-\mathrm{N}=)}$. Vibration bands originating from alkyl groups $\left(v_{\mathrm{CH} 2}\right)$ appear at 2938 $\mathrm{cm}^{-1}$. The IR results confirm the chemical structure of the desired polymers. 


\section{Scheme 1.}

Table 1.

\section{Reaction mixture}

Liquid crystallinity of the reaction mixtures before polymerization (before addition of catalyst) and after polymerization was examined with polarizing optical microscopy (POM) and DSC measurements.

The LC temperature range was evaluated with the DSC measurements (Figure 1). The reaction mixture before polymerization for PA6T[(R)-CLC] showed cholesteric phase at $82-104{ }^{\circ} \mathrm{C}$ on heating, and at $104-73{ }^{\circ} \mathrm{C}$ on cooling. The reaction mixture after polymerization of PA6T $[(R)-C L C]$ exhibited cholesteric phase at $89-117^{\circ} \mathrm{C}$ on heating, and at $105-74{ }^{\circ} \mathrm{C}$ on cooling. Figure 2 displays POM images of the LC reaction mixture for PA6T $[(S)-C L C]$, showing clear LC textures. These results indicate that the reaction was successfully performed in LC phase. Further, we observed phase transition behavior of the LC solution for preparation of polythiophene derivatives having azobenzene with no alkyl spacer, abbreviated as PAT $[(R)-\mathrm{CLC}]$ and PAT $[(S)-\mathrm{CLC}]$ [17]. The LC reaction mixtures before polymerization and after polymerization for $\operatorname{PAT}[(R)-\mathrm{CLC}]$ and $\operatorname{PAT}[(S)-\mathrm{CLC}]$ consistently show mesophase at the polymerization temperature range. These results confirmed that the polymerizations were conducted in cholesteric phase.

Note that the LC mixtures containing monomers show blue phase (BP) at wide temperature range. In general, BP appears at a narrow temperature range, i.e., $1-2{ }^{\circ} \mathrm{C}$, because BP is a frustrated mesophase. However, the LC mixture for PAT $[(R)-C L C]$ in this study showed BP in wide temperature range in cooling process (before addition of 
Ohta, R.; Ohkawa, S.; Goto, H.*

Polymerization of Thiophene Derivatives Bearing Bulky Azobenzene Substituent with Flexible Alkyl Spacer in Liquid Crystal, Int. Nat. J. Polym. Mater. 61:395-409, 2012.

catalyst, $103-89{ }^{\circ} \mathrm{C}$; after polymerization, $94-90{ }^{\circ} \mathrm{C}$ ). And the $\mathrm{LC}$ mixture for $\operatorname{PAT}[(R)-\mathrm{CLC}]$ in heating process shows BP between $99^{\circ} \mathrm{C}$ and $111^{\circ} \mathrm{C}$ under the POM observations. Figure 2 shows optical textures of the LC mixture for PA6T[(R)-CLC]. The POM images exactly appear platelet texture of BP for the LC samples containing monomer before polymerization and after polymerization. However, the DSC detects no clear phase transition signal related with BP [24].

\section{Figure 1.}

\section{Figure 2.}

\section{UV-vis and Photoluminescence}

Table 2 summarizes results of the UV-vis optical absorption and photoluminescence measurements of PA6T $[(R)-\mathrm{CLC}]$, and PA10T $[(R)-\mathrm{CLC}]$ in the form of cast films from chloroform and polymers in chloroform solution $\left(5 \times 10^{-5} \mathrm{M}\right)[25]$.

In UV-vis optical absorption spectra these polymers show two major bands. PA6T $[(R)-C L C]$ displays absorption bands at $355 \mathrm{~nm}$ and $449 \mathrm{~nm}$ for the cast film, and $351 \mathrm{~nm}$ and $452 \mathrm{~nm}$ in chloroform solution. PA10T[(R)-CLC] shows absorption bands at $354 \mathrm{~nm}$ and $449 \mathrm{~nm}$ for the cast film, and $352 \mathrm{~nm}$ and $450 \mathrm{~nm}$ in chloroform solution. These bands at short wavelengths are assignable to $\pi-\pi^{*}$ transition of the aromatic groups [17]. On the other hand, the absorption band at long wavelengths overlaps $\pi-\pi^{*}$ transition of the conjugated main-chain and $n-\pi^{*}$ transition of the azobenzene chromophores.

PA6T $[(R)-C L C]$ and PA10T $[(R)-C L C]$ show photoluminescence in chloroform solution at 552-560 $\mathrm{nm}$ (Table 2), whereas the polymers display no fluorescence in the 
Ohta, R.; Ohkawa, S.; Goto, H.*

Polymerization of Thiophene Derivatives Bearing Bulky Azobenzene Substituent with Flexible Alkyl Spacer in Liquid Crystal, Int. Nat. J. Polym. Mater. 61:395-409, 2012.

form of cast film. This may be due to the fact that the polymers form aggregation in molecular level in the form of cast film, resulting the quench of photoluminescence.

\section{Table 2.}

\section{Photoisomerization of Azobenzene Moiety}

Photoresponsivity of the polymers was examined in chloroform solution upon irradiation of UV light at $370 \mathrm{~nm}$ and visible light at $585 \mathrm{~nm}$ at room temperature. The polymers, PA6T[(R)-CLC] and PA10T[(R)-CLC], display similar behavior of photoisomerization. Figure 3 shows photoisomerization results of PA10T[(R)-CLC] in chloroform solution. Upon irradiation of UV light, the absorption band at $352 \mathrm{~nm}$ weakened, corresponding to trans-cis isomerization of azobenzene (Figure 3a). On the other hand, the absorption band at the $352 \mathrm{~nm}$ strengthened with irradiation of visible light, corresponding to cis-trans isomerization (Figure 3b). The change in molecular form of azobenzene moiety by photoisomerization is indicated in Figure 3 (top). This absorption intensity did not restore to the initial intensity with visible light irradiation after UV light irradiation. The polymers having azobenzene substituent with no flexible spacer prepared in the LC show no photoisomerization behavior. This result indicates that the introduction of the flexible alkyl spacer for the polymers provides ample space for requirements of photoisomerization of azobenzene accompanied by mechanical change in the molecular form.

Figure 3. 


\section{lodine Doping}

The polymers synthesized in this study consist of $\pi$-conjugated main chains. The $\pi$-conjugated system can be doped by electron acceptors [26]. The chemical doping process produces charge carriers. In this section, we examine in-situ iodine (electron acceptor) doping for $\operatorname{PAT}[(R)-C L C]$.

The ESR spectra of PAT $[(R)-C L C]$ show asymmetric Dysonian line shape upon in-situ vapor doping of iodine, as shown in Figures $4 \mathrm{a}$ and $4 \mathrm{~b}$. Figure 5 summarizes change in $g$-value, ESR intensity $\left(I_{p p}\right)$, linewidth $\left(\Delta H_{p p}\right)$, and spin concentration during the chemical doping for PAT $[(R)-C L C]$. The $g$-values are almost constant through the doping process (Figure 5a). The $I_{p p}$ increases rapidly after initial doping followed by decrease in intensity (Figure 5b). In light doping level (less than $95 \mathrm{~min}) \Delta H_{p p}$ value is almost constant, while the $\Delta H_{p p}$ value increases with heavy doping (after $95 \mathrm{~min}$, Figure 5b). The narrow $\Delta H_{p p}$ value in light doping level suggests delocalization of the charge career on the main chain. Here, the doping time of 95 min can be determined as critical point of doping time $\left(\mathrm{T}_{\mathrm{cd}}\right)$ for the present polymer. Spin concentration of the polymer increases in light doping level with time, and the concentration is to be saturated at the heavy doping level, as shown in Figure 5c). This is a typical behavior of doping process with generation of polarons (radical cation) and bipolarons (dication) for conducting polymers [27]. The generation of polarons and bipolarons is illustrated in Figure 6. Generation of polarons along the main-chain increases spin concentration of the polymer in the light doping level (Phase I), resulting the increase of the ESR intensity. Further doping produces bipolarons in the next phase (after 95 min doping, Phase II) [28]. The generation of bipolarons decreases spin concentration of the polymer, 
Ohta, R.; Ohkawa, S.; Goto, H.*

Polymerization of Thiophene Derivatives Bearing Bulky Azobenzene Substituent with Flexible Alkyl Spacer in Liquid Crystal, Int. Nat. J. Polym. Mater. 61:395-409, 2012.

resulting the decrease of the ESR intensity. The doping experiment exactly confirmed that the polymer consists of $\pi$-conjugated system, and the polymer has properties of semiconductors.

Figure 4.

Figure 5.

Figure 6.

\section{Liquid Crystallinity of Polymers}

Liquid crystallinity of the LC medum free polymers synthesized in this study was examined with POM and DSC. PAT $[(R)-C L C]$ and PAT $[(S)$-CLC $]$ show no liquid crystallinity. On the other hand, the polymers having flexible alkyl spacers, PA6T $[(R)-C L C], \quad \operatorname{PA6T}[(S)-C L C], \quad P A 10 T[(R)-C L C]$, and PA10T $[(S)-C L C]$, show mesophase at appropriate temperatures. The polymers show Schlieren texture and thread-like texture typical of nematic phase in both heating and cooling process (Figure 7). These results indicate that the polymer liquid crystal materials were successfully prepared in the liquid crystal medium. This attempt is to be a new reaction and an approach for synthesis of liquid crystalline $\pi$-conjugated polymers in a new view point.

\section{Figure 7.}

\section{CONCLUSIONS}

We successfully synthesized a series of $\pi$-conjugated polymers bearing bulky 
Ohta, R.; Ohkawa, S.; Goto, H.*

Polymerization of Thiophene Derivatives Bearing Bulky Azobenzene Substituent with Flexible Alkyl Spacer in Liquid Crystal, Int. Nat. J. Polym. Mater. 61:395-409, 2012.

azobenzene moiety with flexible alkyl spacer in cholesteric liquid crystals. In-situ vapor-phase doping of iodine for the polymer generated charge carriers, confirming the polymer consists of $\pi$-conjugated system.

Biological systems employ liquid crystallinity for mechanical movement (e.g., muscle). Also, some insects showing structural color have liquid crystal order in their cuticle. Of special interest, biological reactions often progress in anisotropic liquid crystal media in the living organisms. Although, up to now, artificial chemical reactions have been conducted in isotropic solvent in general, the present results demonstrate possibility of polymerization of bulky monomers in liquid crystals and progress for synthesis of liquid crystalline conducting polymers.

\section{Acknowledgements}

The authors thank the Engineering Workshop and the Chemical Analysis Division Research Facility Center for Science and Technology University of Tsukuba for glasswork and NMR measurements.

\section{Measurements}

IR absorption spectra were obtained with a JASCO FT/IR 550 spectrometer. Number-average molecular weights $\left(M_{\mathrm{n}}\right)$, weight average molecular weight $\left(M_{\mathrm{n}}\right)$, and molecular weight distributions $\left(M_{\mathrm{w}} / M_{\mathrm{n}}\right)$ of the polymers were estimated with gel permeation chromatography (GPC) (Agilent, PLgel 5 $\mu \mathrm{m}$ MIXED-C columns) eluted with tetrahydrofuran by polystyrene standard calibration. Differential scanning calorimetry (DSC) curves were obtained with a Seiko Instruments EXSTRAR6000 DSC/TG/DTA. Ultra visible (UV-vis) spectra were recorded on a Hitachi High-Technologies U-3500 spectrophotometer. Fluorescence spectra were recorded on a 
Ohta, R.; Ohkawa, S.; Goto, H.*

Polymerization of Thiophene Derivatives Bearing Bulky Azobenzene Substituent with Flexible Alkyl Spacer in Liquid Crystal, Int. Nat. J. Polym. Mater. 61:395-409, 2012.

Hitachi High-Technologies F-4500. UV-vis and fluorescence spectra of the polymers were obtained at room temperature at a concentration of $5 \times 10^{-5} \mathrm{M}$ in chloroform solution calculated from molecular weight of monomer repeat unit, or cast film of the polymers from chloroform solution. Polarizing optical microscopic images were captured with a Nikon ECLIPSE LV100.

\section{Materials}

3-Thenoic acid (TCI), N-bromosuccinimide (Aldrich), 4-(phenylazo)phenol (TCI), 6-bromo-1-hexanol (TCI), potassium carbonate (Wako), 10-bromo1-decanol (TCI), potassium iodide (Wako), triphenylphosphine (Wako), magnesium sulfate $\left[\mathrm{MgSO}_{4}\right]$

(Wako), diisopropyl-azo-dicarboxylate $(40 \%$ in toluene) (TCI), tetrakis(triphenylphosphine)palladium $(0) \quad\left[\mathrm{Pd}\left(\mathrm{PPh}_{3}\right)_{4}\right](\mathrm{TCI})$ were used as received. Tetrahydrofuran (THF), and diethyl ether were purified by distillation before use. $\mathrm{CH}_{2} \mathrm{Cl}_{2}$ was dehydrated by $\mathrm{MgSO}_{4}$ prior to use. Ethanol, acetone and methanol were used as received.

\section{PA6T[(R)-CLC].}

$(R)$-CLC $(0.447 \mathrm{~g}, 1.00 \mathrm{mmol})$ was added in a small Schlenk flask and heated to over $130{ }^{\circ} \mathrm{C}$ under an argon atmosphere. Then, A6T $(0.057 \mathrm{~g}, 0.10 \mathrm{mmol})$ and SBT $(0.049 \mathrm{~g}$, $0.10 \mathrm{mmol})$ as monomers were added into $(R)$-CLC, and allowed to cool to $97{ }^{\circ} \mathrm{C}$, followed by the addition of $\left[\mathrm{Pd}\left(\mathrm{PPh}_{3}\right)_{4}\right]\left(1.51 \mathrm{mg}, 1.31 \times 10^{-3} \mathrm{mmol}\right)$. The mixture was stirred at $75 \mathrm{rpm}$ for $24 \mathrm{~h}$ at $97^{\circ} \mathrm{C}$. After the reaction, the mixture was allowed to cool to room temperature, and a small amount of acetone was added. The solution was added to ca. $70 \mathrm{~mL}$ acetone and washed for $4 \mathrm{~h}$. After several days, the crude product was 
Ohta, R.; Ohkawa, S.; Goto, H.*

Polymerization of Thiophene Derivatives Bearing Bulky Azobenzene Substituent with Flexible Alkyl Spacer in Liquid Crystal, Int. Nat. J. Polym. Mater. 61:395-409, 2012.

precipitated. The acetone was decanted off, and the precipitate was further washed by acetone in a similar manner. The acetone was decanted off again, and the crude product was further washed in ca. $80 \mathrm{~mL}$ methanol. After decantation and dried in vacuo, PA6T $\left[(R)\right.$-CLC] was obtained as red powder $\left(0.033 \mathrm{~g}, 5.8 \times 10^{-2} \mathrm{mmol}\right.$, yield $\left.58 \%\right)$. IR $\left(\mathrm{cm}^{-1}, \mathrm{KBr}\right): 3064\left(v_{\mathrm{CH}}\right), 2938\left(v_{\mathrm{CH} 2}\right), 2860\left(v_{\mathrm{CH} 2}\right), 1707$ ( $\left.v_{-\mathrm{CO}-\mathrm{O}-}\right), 1599\left(v_{\text {phenyl ring }}\right), 1578$ $\left(v_{\text {phenyl ring }}\right), 1499\left(v_{\text {phenyl ring, } \mathrm{N}=\mathrm{N}}\right), 1473\left(\gamma_{\mathrm{CH} 2}\right), 1459\left(v_{\text {phenyl ring, } \mathrm{N}=\mathrm{N}}\right), 1439\left(v_{\mathrm{N}=\mathrm{N}}\right), 1249$ $\left(v_{\mathrm{C}-\mathrm{O}, \mathrm{CH}}\right), 1198\left(v_{=\mathrm{C}-\mathrm{O}}\right), 1139\left(v_{\mathrm{C}-\mathrm{O}-\mathrm{C},-\mathrm{C}-\mathrm{N}=}\right), 1068\left(v_{\mathrm{CH}}\right), 838\left(\delta_{\mathrm{CH}}\right), 790,768\left(\delta_{\mathrm{CH}}\right), 721$ $\left(\gamma_{\mathrm{CH} 2}\right), 688\left(\delta_{\mathrm{CH}, \mathrm{C}-\mathrm{C}}\right), 548$.

\section{PA6T[(S)-CLC].}

PAT $[(S)-C L C]$ was synthesized from A6T $(0.057 \mathrm{~g}, 0.10 \mathrm{mmol})$ and SBT $(0.049 \mathrm{~g}, 1.0$ $\mathrm{mmol})$ in $(S)$-CLC $(0.447 \mathrm{~g}, 1.00 \mathrm{mmol})$ in the same method for preparation of PA6T $[(R)-C L C]$. Yield $=56 \%\left(\right.$ red powder, $\left.0.032 \mathrm{~g}, 5.5 \times 10^{-2} \mathrm{mmol}\right) . \mathrm{IR}\left(\mathrm{cm}^{-1}, \mathrm{KBr}\right)$ : $3063\left(v_{\mathrm{CH}}\right), 2938\left(v_{\mathrm{CH} 2}\right), 2861\left(v_{\mathrm{CH} 2}\right), 1707$ ( $\left.v_{-\mathrm{CO}-\mathrm{O}-}\right), 1599$ ( $\left.v_{\text {phenyl ring }}\right), 1579\left(v_{\text {phenyl ring }}\right)$, $1499\left(v_{\text {phenyl ring, } \mathrm{N}=\mathrm{N}}\right), 1466\left(\gamma_{\mathrm{CH} 2}\right), 1461\left(v_{\text {phenyl ring, } \mathrm{N}=\mathrm{N}}\right), 1440\left(v_{\mathrm{N}=\mathrm{N}}\right), 1248\left(v_{\mathrm{C}-\mathrm{O}, \mathrm{CH}}\right)$, $1196\left(v_{=\mathrm{C}-\mathrm{O}}\right), 1139\left(v_{\mathrm{C}-\mathrm{O}-\mathrm{C},-\mathrm{C}-\mathrm{N}=}\right), 1068\left(v_{\mathrm{CH}}\right), 1000,836\left(\delta_{\mathrm{CH}}\right), 789,767\left(\delta_{\mathrm{CH}}\right), 721$ $\left(\gamma_{\mathrm{CH} 2}\right), 687\left(\delta_{\mathrm{CH}, \mathrm{C}-\mathrm{C}}\right), 547$.

\section{PA10T[(R)-CLC $]$.}

$(R)$-CLC (0.449 g, $1.01 \mathrm{mmol})$ was added in a small Schlenk flask and heated over 140 ${ }^{\circ} \mathrm{C}$, and allowed to cool to $92{ }^{\circ} \mathrm{C}$ under an argon atmosphere. Then, A10T (0.063 g, 0.10 $\mathrm{mmol})$ and SBT $(0.049 \mathrm{~g}, 0.10 \mathrm{mmol})$ as monomers were added into $(R)$-CLC, followed by the addition of $\left[\mathrm{Pd}\left(\mathrm{PPh}_{3}\right)_{4}\right]\left(1.41 \mathrm{mg}, 1.22 \times 10^{-3} \mathrm{mmol}\right)$. The mixture stirred at 75 rpm for $24 \mathrm{~h}$ at $92{ }^{\circ} \mathrm{C}$. After the reaction, the mixture was allowed to cool to room 
Ohta, R.; Ohkawa, S.; Goto, H.*

Polymerization of Thiophene Derivatives Bearing Bulky Azobenzene Substituent with Flexible Alkyl Spacer in Liquid Crystal, Int. Nat. J. Polym. Mater. 61:395-409, 2012.

temperature, and a small amount of acetone was added. The solution was poured into ca. $70 \mathrm{~mL}$ acetone and stirred to wash for $4 \mathrm{~h}$. After several days, the crude product was precipitated in the solution. The acetone was decanted off, and the precipitate was washed further by acetone in the similar manner. The acetone was decanted off again, and the crude product was father washed in ca. $80 \mathrm{~mL}$ methanol. After decantation and dried in vacuo, PA10T[(R)-CLC $]$ was obtained as red powder $\left(0.040 \mathrm{~g}, 6.3 \times 10^{-2} \mathrm{mmol}\right.$, yield $63 \%)$. IR $\left(\mathrm{cm}^{-1}, \mathrm{KBr}\right): 3063\left(v_{\mathrm{CH}}\right), 2923\left(v_{\mathrm{CH} 2}\right), 2852\left(v_{\mathrm{CH} 2}\right), 1707\left(v_{-\mathrm{CO}-\mathrm{O}-}\right), 1600$ $\left(v_{\text {phenyl ring }}\right), 1578\left(v_{\text {phenyl ring }}\right), 1499\left(v_{\text {phenyl ring, } \mathrm{N}=\mathrm{N}}\right), 1491\left(v_{\text {phenyl ring, } \mathrm{N}=\mathrm{N}}\right), 1466\left(v_{\text {phenyl ring, }}\right.$

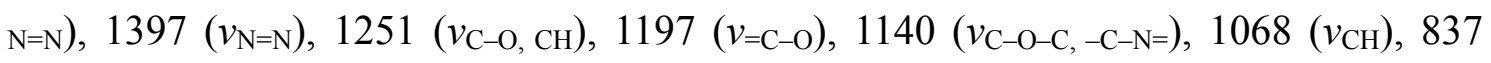
$\left(\delta_{\mathrm{CH}}\right), 790,768\left(\delta_{\mathrm{CH}}\right), 721\left(\gamma_{\mathrm{CH} 2}\right), 688\left(\delta_{\mathrm{CH}, \mathrm{C}-\mathrm{C}}\right), 547$.

\section{PA10T[(S)-CLC].}

$\operatorname{PAT}[(S)-C L C]$ was synthesized from A10T $(0.062 \mathrm{~g}, 0.99 \mathrm{mmol})$ and SBT $(0.049 \mathrm{~g}$, $0.99 \mathrm{mmol})$ in $(S)$-CLC $(0.449 \mathrm{~g}, 1.01 \mathrm{mmol})$ in the same method for preparation of PA10T[(R)-CLC $].$ Yield $=66 \%\left(\right.$ red powder, $\left.0.042 \mathrm{~g}, 6.6 \times 10^{-2} \mathrm{mmol}\right) .{ }^{1} \mathrm{H} \mathrm{NMR}$ $\begin{array}{llllll}\left(\mathrm{CDCl}_{3}\right): & \delta & 1.30 & \left(\mathrm{COO}\left(\mathrm{CH}_{2}\right)_{2}\left(\mathrm{CH}_{2}\right)_{6}\left(\mathrm{CH}_{2}\right)_{2} \mathrm{O}, \quad \mathrm{m}, \quad 12 \mathrm{H}\right), \quad 1.79\end{array}$

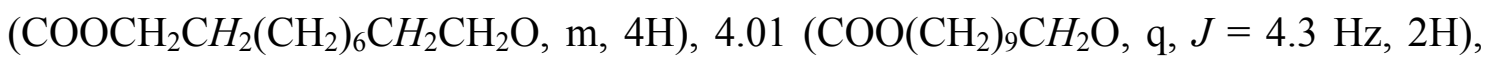
$4.24\left(\mathrm{COOCH}_{2}\left(\mathrm{CH}_{2}\right)_{9} \mathrm{O}, \mathrm{t}, J=6.6 \mathrm{~Hz}, 2 \mathrm{H}\right), 6.98(\mathrm{C}(\mathrm{ph} 2,6) H, \mathrm{dd}, \mathrm{J}=3.1 \mathrm{~Hz}, 2 \mathrm{H}), 7.11$ (C(thio) $H, \mathrm{~m}, 3 \mathrm{H}), 7.33$ (C(thio) $H, \mathrm{~m}, 1 \mathrm{H}), 7.46\left(\mathrm{C}\left(\mathrm{ph}^{\prime}, 4^{\prime}, 5^{\prime}\right) H, \mathrm{C}(\right.$ thio $\left.) H, \mathrm{~m}, 4 \mathrm{H}\right)$, $7.88\left(\mathrm{C}\left(\mathrm{ph} 3,5,2^{\prime}, 6^{\prime}\right) H, \mathrm{~m}, 4 \mathrm{H}\right) . \mathrm{IR}\left(\mathrm{cm}^{-1}, \mathrm{KBr}\right): 3066\left(v_{\mathrm{CH}}\right), 2924\left(v_{\mathrm{CH} 2}\right), 2852\left(v_{\mathrm{CH} 2}\right)$, $1708\left(v_{-\mathrm{CO}-\mathrm{O}-}\right), 1600\left(v_{\text {phenyl ring }}\right), 1578\left(v_{\text {phenyl ring }}\right), 1499\left(v_{\text {phenyl ring, } \mathrm{N}=\mathrm{N}}\right), 1491\left(v_{\text {phenyl ring, }}\right.$ $\mathrm{N}=\mathrm{N}), 1466\left(v_{\text {phenyl ring, } \mathrm{N}=\mathrm{N}}\right), 1397\left(v_{\mathrm{N}=\mathrm{N}}\right), 1250\left(v_{\mathrm{C}-\mathrm{O}, \mathrm{CH}}\right), 1198\left(v_{=\mathrm{C}-\mathrm{O}}\right), 1140\left(v_{\mathrm{C}-\mathrm{O}-\mathrm{C},}\right.$ $\left.{ }_{-\mathrm{C}-\mathrm{N}=}\right), 1068\left(v_{\mathrm{CH}}\right), 838\left(\delta_{\mathrm{CH}}\right), 790,769\left(\delta_{\mathrm{CH}}\right), 721\left(\gamma_{\mathrm{CH} 2}\right), 689\left(\delta_{\mathrm{CH}, \mathrm{C}-\mathrm{C}}\right), 548$. 


\section{Light irradiation}

UV light was irradiated to the solution sample in a quartz cell or cast films with ultra violet light emitting diode (LED) $\left(363<\lambda<370 \mathrm{~nm}, 4 \mathrm{~mW} / \mathrm{cm}^{2}\right.$, NS365L-3RLQ, NITRIDE SEMICONDUCTORS Co., Ltd.). Visible light irradiation for the polymers was carried out with yellow LED $\left(\lambda_{\max }=585 \mathrm{~nm}\right)$.

\section{REFERENCES}

[1] Angioloni L., Caretti D., Giorgini L., Salatelli E., Altomare A., Carlini C., and Solaro R. Polymer 39, 6621-6629 (1998).

[2] Minoura N., Idei K., Rachkov A., Choi Y. W., Ogiso M., and Matsuda K. Macromolecules 37, 9571-9576(2004).

[3] Kurihara S., Yoshioka T., Zahangir A. M., Ogata T., and Nonaka T. J. Appl. Polym. Sci. 92, 2577-2580 (2004).

[4] Bobrovsky A., and Shibaev V. Polymer 47, 4310-4317 (2006).

[5] Fujii T., Shiotsuki M., Inai Y., Sanda F., and Masuda T. Macromolecules 40, 7079-7088 (2007).

[6] Ikeda T., Mamiya J., and Yu Y. Angew. Chem. Int. Ed. 46, 506-528 (2007).

[7] Joost de Wit J., van Ekenstein G. A., Polushkin E., Kvashnina K., Bras W., Ikkala O., and ten Brinke G. Macromolecules 41, 4200-4204(2008).

[8] van Oosten C. L., Corbett D., Davies D., Warner M., Bastiaansen C. W. M., Dirk D. J., and Broer J. Macromolecules 41, 8592-8596 (2008).

[9] Deng W., Pierre-Antoine Albouy P. A., Lacaze E., Keller P., Xiaogong Wang X., 
Ohta, R.; Ohkawa, S.; Goto, H.*

Polymerization of Thiophene Derivatives Bearing Bulky Azobenzene Substituent with Flexible Alkyl Spacer in Liquid Crystal, Int. Nat. J. Polym. Mater. 61:395-409, 2012.

and Li M. H. Macromolecules 41, 2459-2466 (2008).

[10] Langeveld-Voss B. M. W., Janssen R. A. J., and Meijer E. W. J. Mol. Struct. 521, 285-301 (2000).

[11] Kiriy N., Ja1hne E., Adler H. J., Schneider M., Kiriy A., Gorodyska G., Minko S., Jehnichen D., Simon P., Fokin A. A., and Stamm M. Nano Lett. 3, 707-712 (2003).

[12] Wang B., Watt S., Hong M., Domercq B., Sun R., Kippelen B., David D. M., and Collard M. Macromolecules 41, 5156-5165 (2008).

[13] Vangheluwe M., Verbiest T., and Koeckelberghs G. J. Polym. Sci. Part A Polym. Chem. 46, 4817-4829 (2008).

[14] Goto H., Togashi F., Tsujimoto A., Ohta R., and Kawabata, K. Liq. Cryst. 35, $847-856$ (2008).

[15] Togashi F., Ohta R., and Goto H. Tetrahedron Lett. 48, 2559-2562 (2007).

[16] Goto H. Macromolecules 40, 1377-1385 (2007).

[17] Ohta R., Togashi F., and Goto H. Macromolecules 40, 5228-5230 (2007).

[18] a) Yoneyama H., Kawabata K., Tsujimoto A., and Goto H. Electrochem. Commun. 10, 965-969 (2008); b) Goto, H. Adv. Func. Mater. 19, 1335-1342 (2009).

[19] a) Ohkawa S., Ohta R., Kawabata K., and Goto H. Polymer. 2, 393-406 (2010); b)

Goto H., and Ohta R. Macromol. Chem. Phys. 35, 847-856 (2008).

[20] a) Kosugi M., Sasazawa K., Shimizu Y., and Migita T. Chem. Lett. (1977) 301-302; b) Milstein D. and Stille J. K. J. Am. Chem. Soc. (1978), 100, 3636-3638.

[21] Kuiper J. M., Hulst R., and Engberts J. B. F. N. Synthesis 5, 695-698 (2003).

[22] Kuvshinova S. A., Zav'yalov A. V., Koifman O. I., Aleksandriiskii V. V., and Burmistrov V. A. R. J. Org. Chem., 40, 1113-1116 (2004).

[23] Rahman M. L., Tschierske C., Yusoff M., and Silong S. Tetrahedron Lett. 46, 
Ohta, R.; Ohkawa, S.; Goto, H.*

Polymerization of Thiophene Derivatives Bearing Bulky Azobenzene Substituent with Flexible Alkyl Spacer in Liquid Crystal, Int. Nat. J. Polym. Mater. 61:395-409, 2012.

2303-2306 (2005).

[24] Generally, DSC can not detect phase transition related with BP very well.

[25] Poor solubility in chloroform.

[26] Shirakawa H., Louis E., MacDiarmid A. G., Chiang C. K., and Heeger A. J. J. Chem. Soc. Chem. Commun. 1977, 578-580 (1977).

[27] Ohsawa T., Kaneto K., and Yoshino K. Jpn. J. Appl. Phys. 23, L663-L65 (1984).

[28] Polarons and bipolarons coexist at particular contents. 
Ohta, R.; Ohkawa, S.; Goto, H.*

Polymerization of Thiophene Derivatives Bearing Bulky Azobenzene Substituent with Flexible Alkyl Spacer in Liquid Crystal, Int. Nat. J. Polym. Mater. 61:395-409, 2012.<smiles>[R]OC(=O)c1cc(Br)sc1Br</smiles>

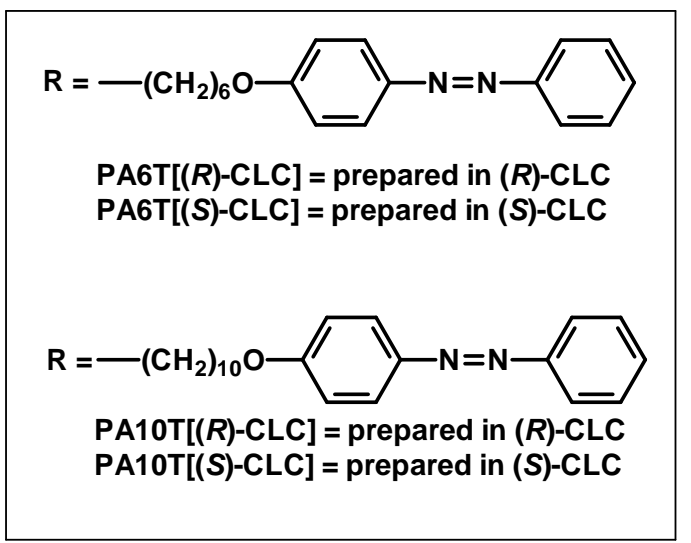

Scheme 1. Polymerization in cholesteric liquid crystal. 
Table 1: Polymerization results.

\begin{tabular}{|c|c|c|c|c|}
\hline Polymer & Yield (\%) & $M_{\mathrm{n}}^{[\mathrm{a}]}$ & $M_{\mathrm{w}}^{[\mathrm{b}]}$ & $M_{\mathrm{w}} / M_{\mathrm{n}}^{[\mathrm{c}]}$ \\
\hline PA6T[(R)-CLC] & 58 & 1,500 & 2,100 & 1.4 \\
\hline PA6T[(S)-CLC] & 56 & 1,500 & 2,200 & 1.4 \\
\hline PA10T[(R)-CLC] & 63 & 2,200 & 3,500 & 1.6 \\
\hline PA10T[(S)-CLC] & 66 & 1,800 & 2,300 & 1.3 \\
\hline $\begin{array}{l}\text { [a] Number-average } \\
\text { standard. } \\
{ }^{[\mathrm{b}]} \text { Molecular weight } \\
{ }^{[\mathrm{c}]} \text { Molecular weight } \\
{\left[{ }^{\mathrm{dd}]} \text { Degree of polym }\right.}\end{array}$ & $\begin{array}{l}\text { ecular wei } \\
\text { uated rela } \\
\text { ibution rel } \\
\text { tion relativ }\end{array}$ & $\begin{array}{l}\text { valuate } \\
\text { o PS sta } \\
\text { to PS st } \\
\text { PS stanc }\end{array}$ & & \\
\hline
\end{tabular}


Ohta, R.; Ohkawa, S.; Goto, H.*

Polymerization of Thiophene Derivatives Bearing Bulky Azobenzene Substituent with Flexible Alkyl Spacer in Liquid Crystal, Int. Nat. J. Polym. Mater. 61:395-409, 2012.

Table 2: Optical data of PA6T[(R)-CLC] and PA10T[(R)-CLC]

\begin{tabular}{cccccc}
\hline Polymer & \multicolumn{4}{c}{ Optical absorption } & Photoluminescence \\
\cline { 2 - 6 } & \multicolumn{3}{c}{ Film } & In $\mathrm{CH}_{2} \mathrm{Cl}_{2}$ & In $\mathrm{CH}_{2} \mathrm{Cl}_{2}$ \\
& Peak & $\lambda_{\max }$ & Peak & $\lambda_{\max }$ & $\lambda_{\max }$ \\
\hline PA6T[(R)-CLC] & 355 & 449 & 351 & 452 & 556 \\
PA10T[(R)-CLC] & 354 & 449 & 352 & 450 & 554 \\
\hline
\end{tabular}


Ohta, R.; Ohkawa, S.; Goto, H.*

Polymerization of Thiophene Derivatives Bearing Bulky Azobenzene Substituent with Flexible Alkyl Spacer in Liquid Crystal, Int. Nat. J. Polym. Mater. 61:395-409, 2012.

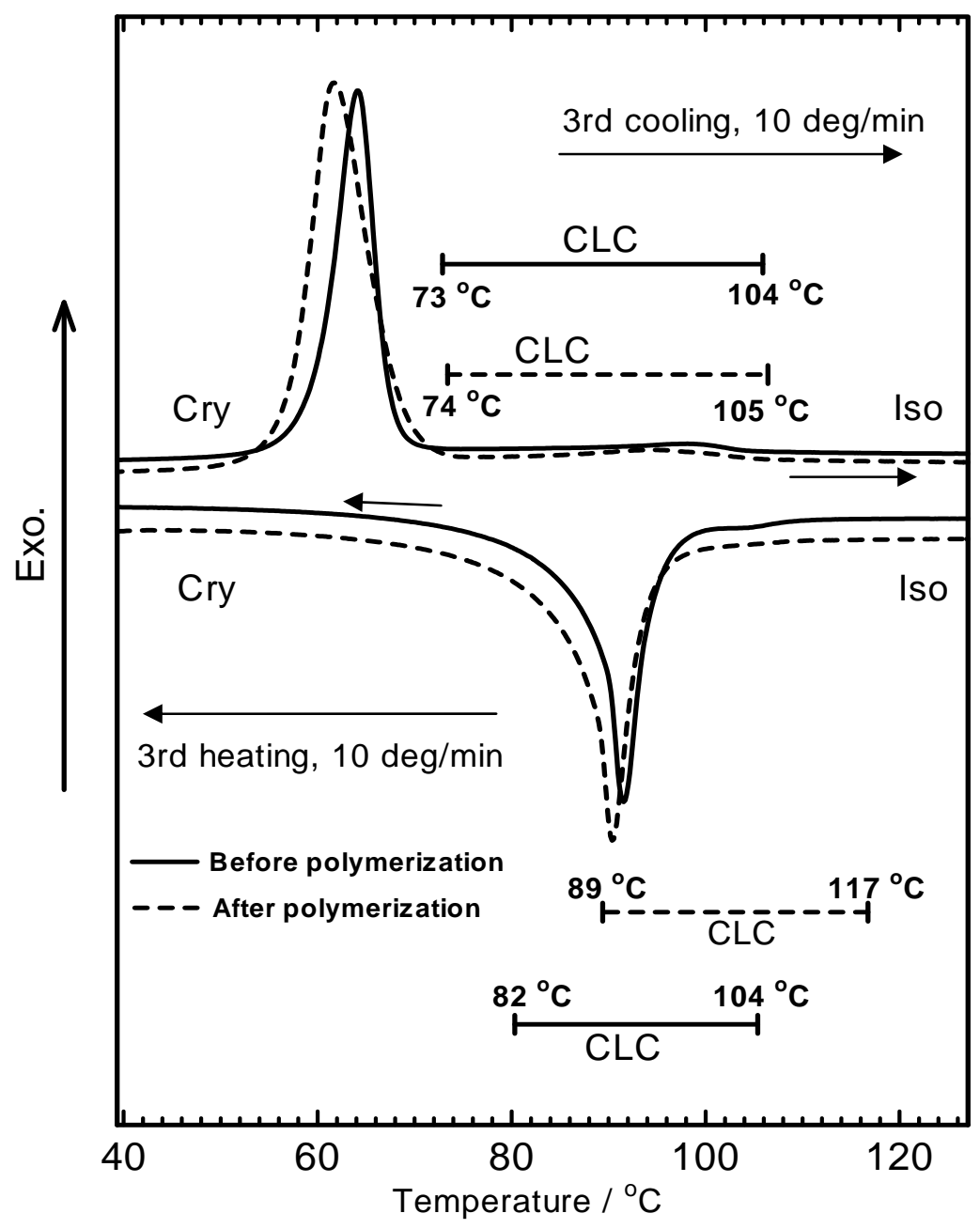

Figure 1: DSC curves of the LC solution before and after polymerization of PA6T $[(R)-C L C]$ 
Ohta, R.; Ohkawa, S.; Goto, H.*

Polymerization of Thiophene Derivatives Bearing Bulky Azobenzene Substituent with Flexible Alkyl Spacer in Liquid Crystal, Int. Nat. J. Polym. Mater. 61:395-409, 2012.

(a) Heating

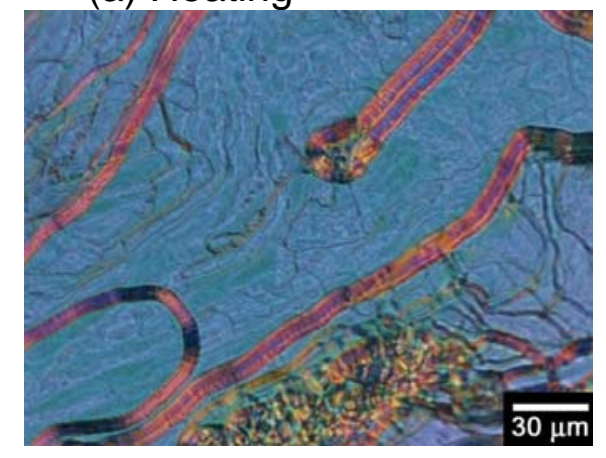

(c) Cooling

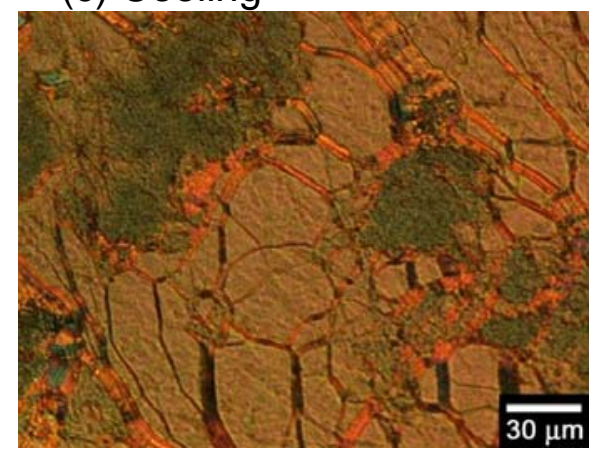

(b) Cooling

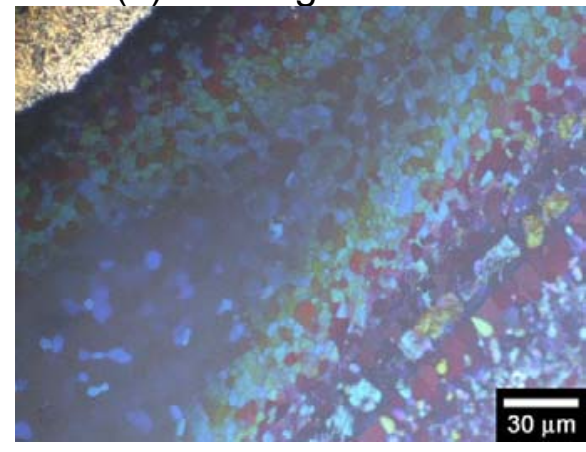

Before

polymerization

(before addition

of catalyst)

Figure 2: POM image of the LC solution for PA6T[(S)-CLC] in heating process before polymerization (before addition of catalyst) at $94{ }^{\circ} \mathrm{C}$ (a). LC solution for PA6T[(S)-CLC] before polymerization in cooling process at $102{ }^{\circ} \mathrm{C}(b) . \mathrm{LC}$ solution for PA6T[(S)-CLC] in cooling process after polymerization at $95^{\circ} \mathrm{C}(\mathrm{c})$. LC solution for PA6T[(S)-CLC] after polymerization in cooling process at $103^{\circ} \mathrm{C}$ (d). 
Ohta, R.; Ohkawa, S.; Goto, H.*

Polymerization of Thiophene Derivatives Bearing Bulky Azobenzene Substituent with Flexible Alkyl Spacer in Liquid Crystal, Int. Nat. J. Polym. Mater. 61:395-409, 2012.
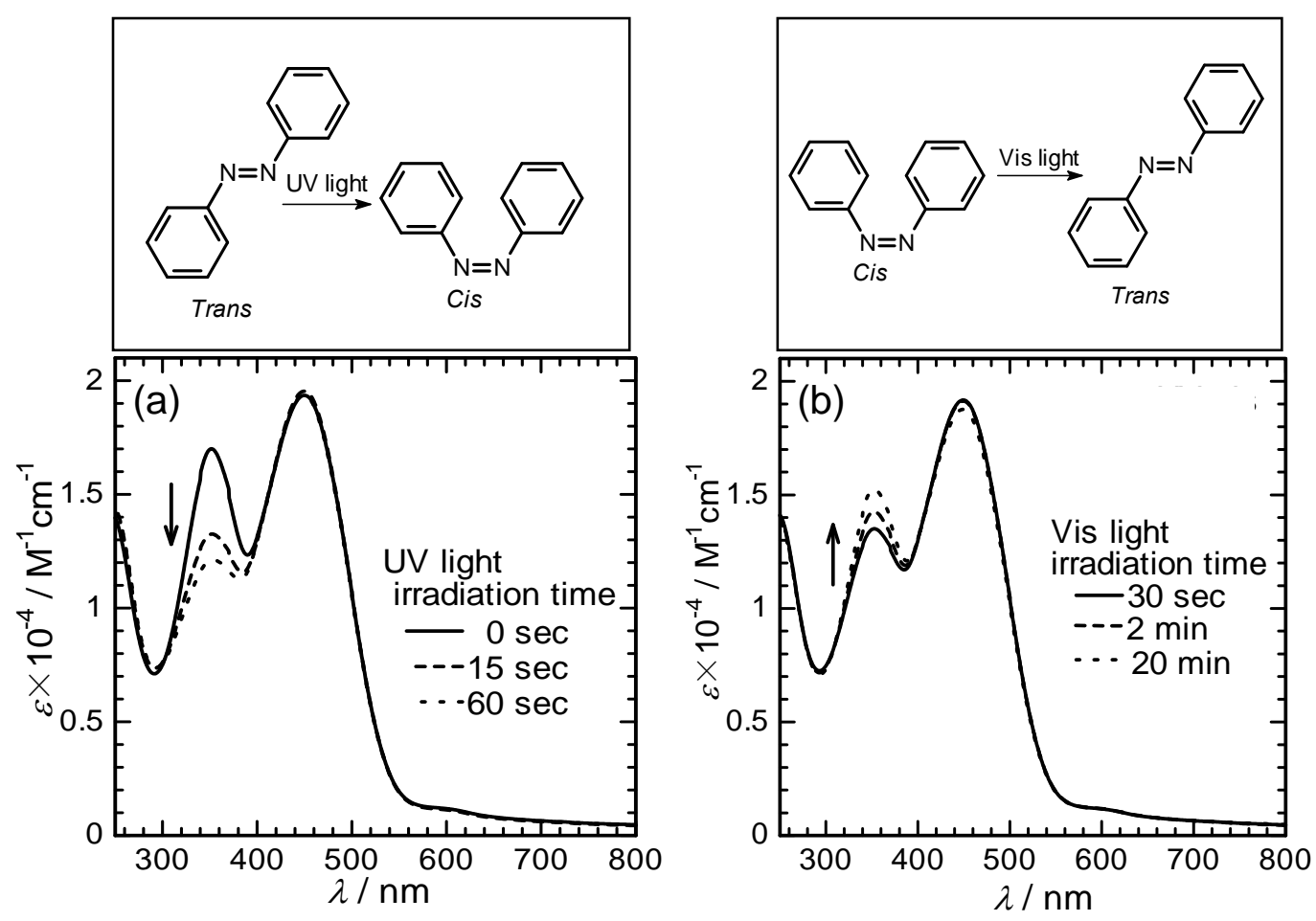

Figure 3: The change in molecular form of azobenzene moiety by photoisomerization (Top). Optical absorption spectra of PA10T[(R)-CLC] under UV light irradiation (a), and PA10T[(R)-CLC] under visible light irradiation(b). 
Ohta, R.; Ohkawa, S.; Goto, H.*

Polymerization of Thiophene Derivatives Bearing Bulky Azobenzene Substituent with Flexible Alkyl Spacer in Liquid Crystal, Int. Nat. J. Polym. Mater. 61:395-409, 2012.

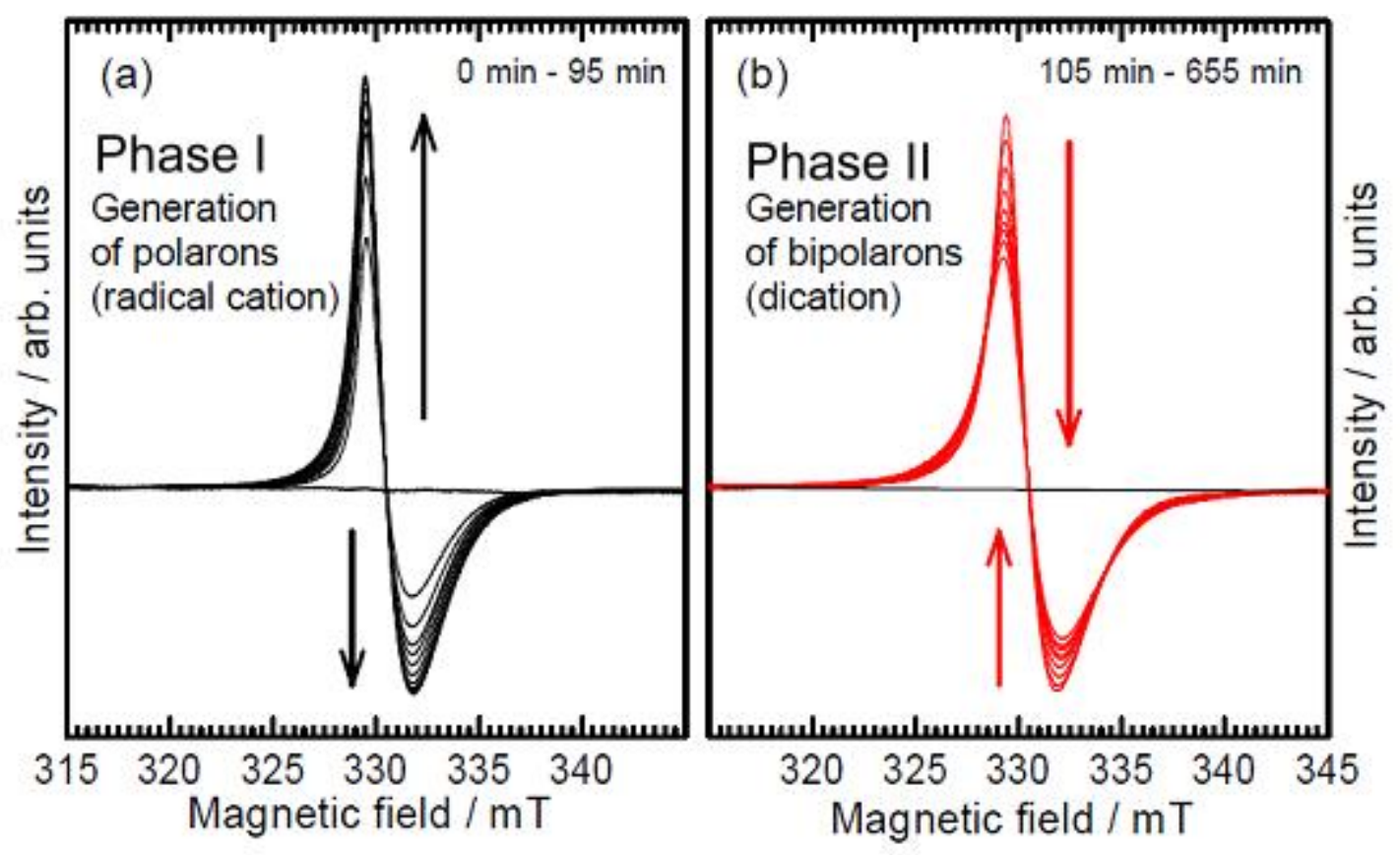

Figure 4: In-situ ESR spectra of PAT $[(R)-C L C]$ during vapor-phase doping of iodine. $\Delta H_{p p}$ vs. doping time (a). Change in ESR signal upon doping (c, d). 
Ohta, R.; Ohkawa, S.; Goto, H.*

Polymerization of Thiophene Derivatives Bearing Bulky Azobenzene Substituent with Flexible Alkyl Spacer in Liquid Crystal, Int. Nat. J. Polym. Mater. 61:395-409, 2012.

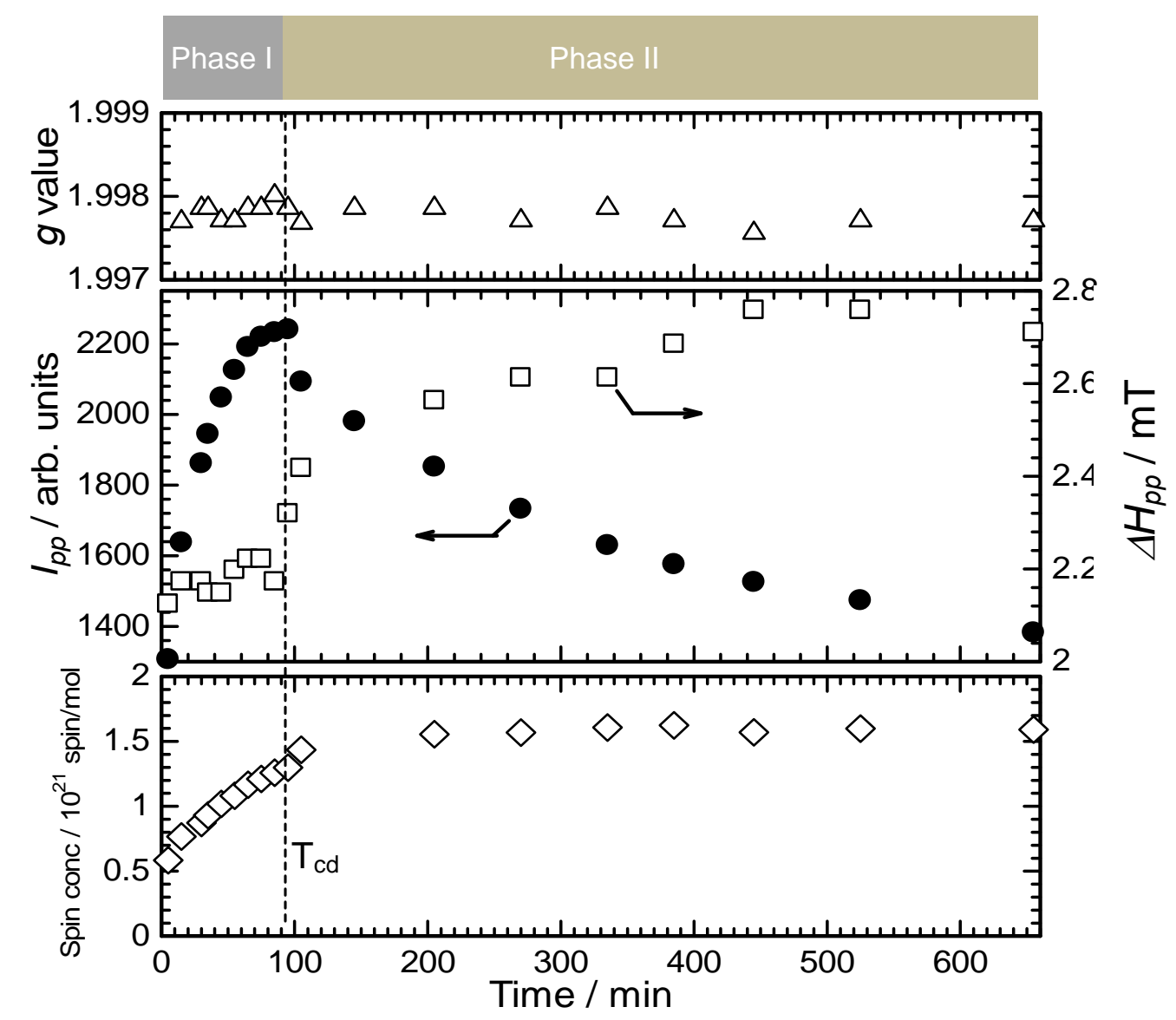

Figure 5: ESR results of in-situ vapor doping of iodine for PAT[(R)-CLC]. Change in $g$-value (a), ESR intensity $\left(I_{p p}\right)(\mathrm{b})$, line width $\left(\Delta H_{p p}\right)(\mathrm{b})$, and spin concentration (c). 
Ohta, R.; Ohkawa, S.; Goto, H.*

Polymerization of Thiophene Derivatives Bearing Bulky Azobenzene Substituent with Flexible Alkyl Spacer in Liquid Crystal, Int. Nat. J. Polym. Mater. 61:395-409, 2012.

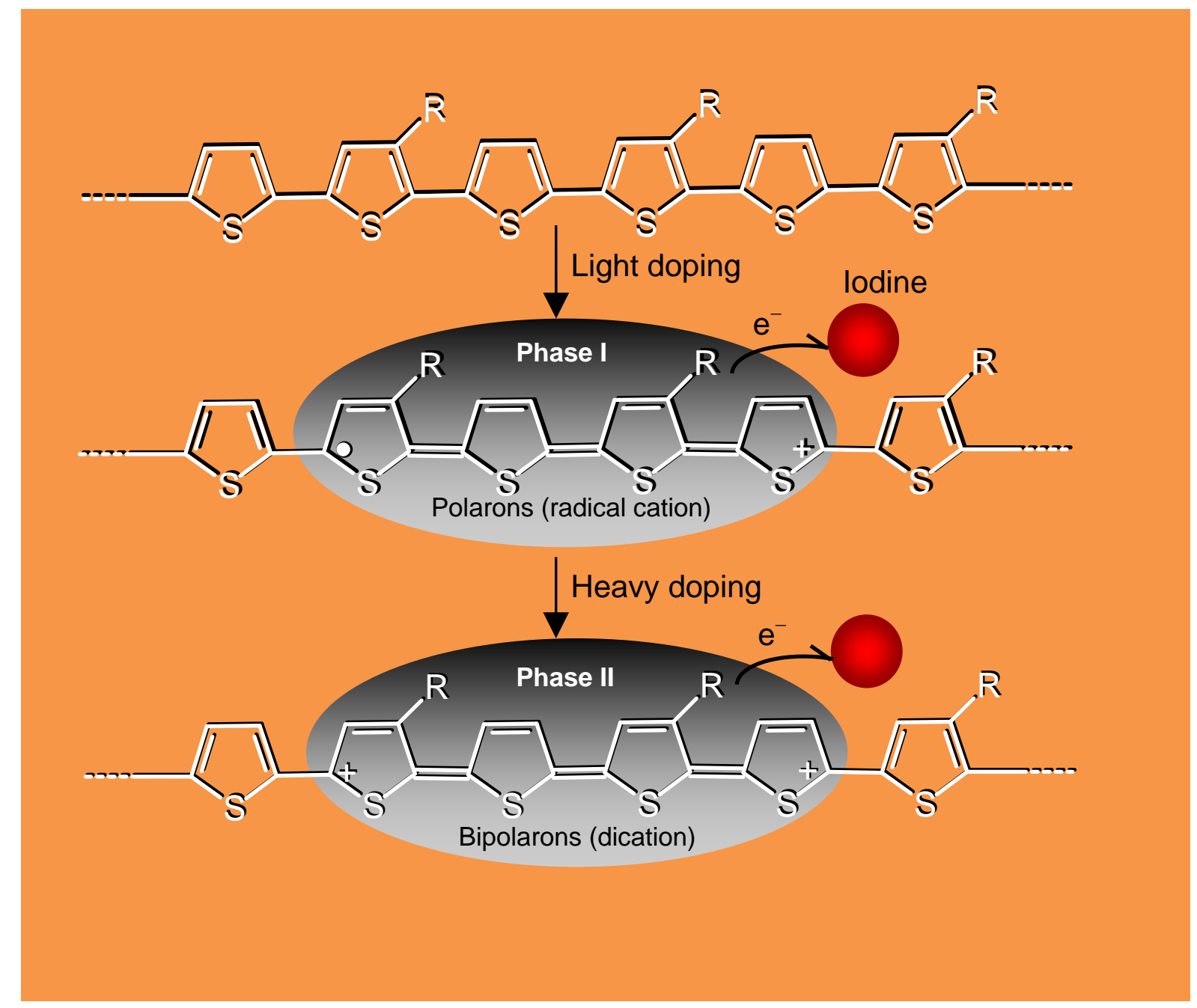

Figure 6: Generation of polarons (radical cation) and bipolarons (dication) by electron acceptor doping (iodine). $\mathrm{R}=$ substituent. 
Ohta, R.; Ohkawa, S.; Goto, H.*

Polymerization of Thiophene Derivatives Bearing Bulky Azobenzene Substituent with Flexible Alkyl Spacer in Liquid Crystal, Int. Nat. J. Polym. Mater. 61:395-409, 2012.
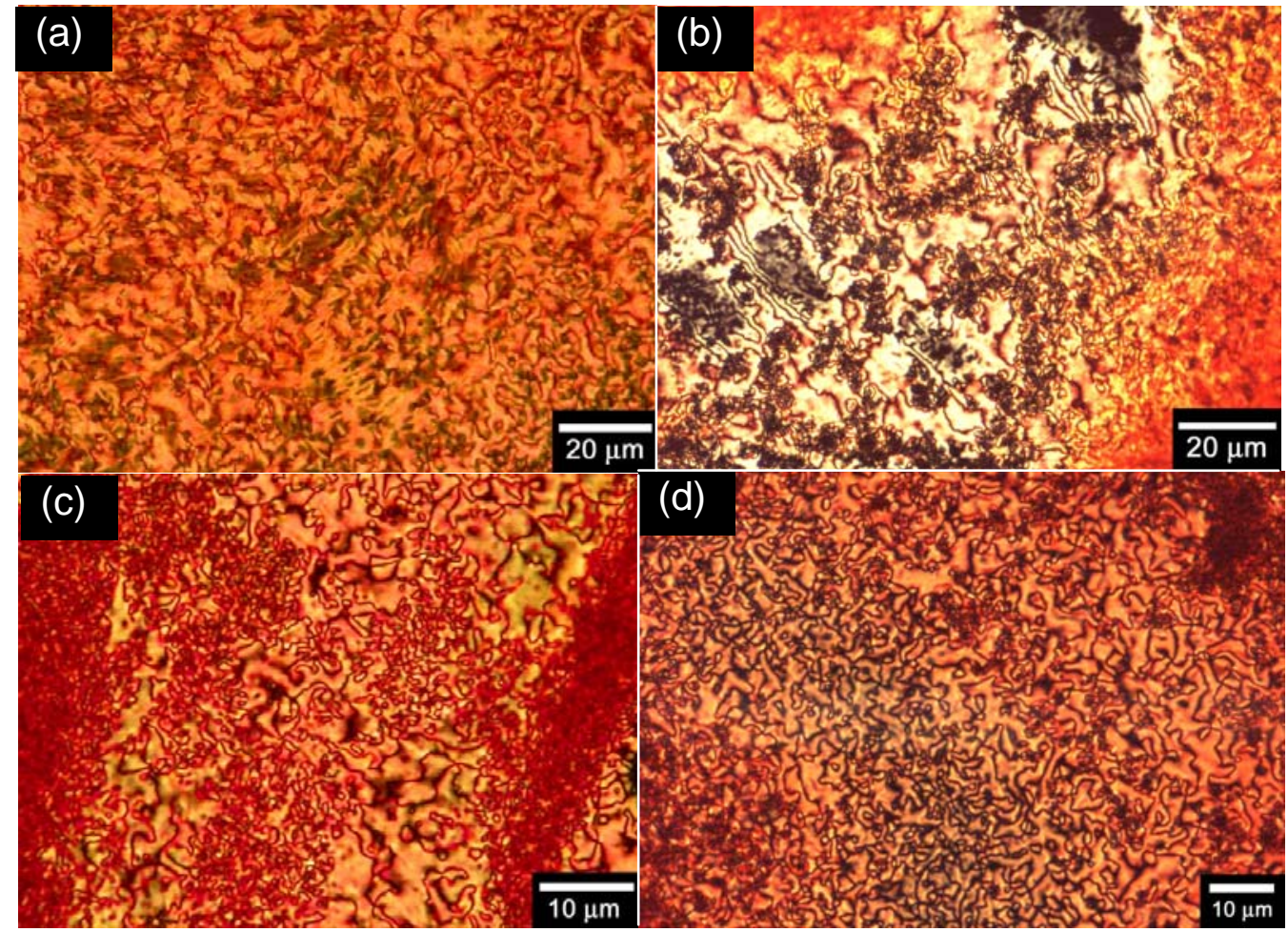

Figure 7: Polarizing optical microscopic image of PA6T[(R)-CLC] (a), PA6T[(S)-CLC] (b), PA10T[(R)-CLC] (c), and PA10T[(S)-CLC] (d) in cooling process from isotropic state. 